\title{
RAPD Analysis for Genetic Diversity and Verification of Hybridity in Cowpea [Vigna unguiculata (L.) Walp.]
}

\author{
U. B. Pethe ${ }^{1 *}$, N. S. Dodiya ${ }^{2}$, S. G. Bhave ${ }^{3}$ and S. V. Sawardekar ${ }^{4}$ \\ ${ }^{1}$ Department of Plant Breeding and Genetics, Rajasthan College of Agriculture, \\ Udaipur, India \\ ${ }^{2}$ Department of $P B \& G, R C A$, Udaipur-313001, India \\ ${ }^{3}$ Director of Extension Education, Dr B.S. Konkan Krishi Vidyapeeth, Dapoli (M.S.), India \\ ${ }^{4}$ Dr B.S. Konkan Krishi Vidyapeeth, Dapoli (M.S.), India \\ *Corresponding author
}

\section{A B S T R A C T}

Cowpea (Vigna unguiculata) is a legume crop growing in almost all parts of world including tropics and subtropics. This study was thus undertaken to assess genetic diversity among the different parents used for

\section{Keywords}

Cowpea, Genetic diversity, RAPD markers, Hybridity

Article Info

Accepted:

22 July 2020

Available Online:

10 August 2020 hybridization and confirmation of hybrids of cowpea (Vigna unguiculata) by using randomly amplified polymorphic DNA (RAPD) markers. RAPD profiles for 11 genotypes were generated with 20 random decamer primers. Out of 20 primers screened 15 primers gave scorable DNA fragments and each of the 15 primers revealed various levels of polymorphism. These primers generated 476 DNA fragments in the average range of $167 \mathrm{bp}$ to $3300 \mathrm{bp}$, of which 367 were polymorphic. The percentage of polymorphism ranged from 35.29 to $100 \%$ with an average of $79.96 \%$. The overall range of similarity among 11 genotypes was found to be very wide, ranging from 0.328 to 0.613 which indicates there was high variability among the cowpea genotypes under study. The RAPD primer OPA-18 was effectively used for confirmation of hybridity.

\section{Introduction}

Cowpea (Vigna unguiculata) cowpea, is a highly variable legume crop that originated in Africa. It is mainly grown for grain, forage and green manure. Its grain is rich in protein and digestible carbohydrates and its energy content is nearly equal to that of cereal grains. The genetic variability for different characters are at most importance in selecting the desired genotypes for any breeding programme. Information on genetic variability among different characters is essential for systematic breeding programme. Several different 
methods for documenting genetic information are isozyme analysis, restriction fragment length polymorphisms (RFLP) and random amplified polymorphic DNA (RAPD). The RAPD technique employs $8-10$ base pair random primers to locate random segments of genomic DNA to reveal polymorphisms. It is a simple, reliable and relatively straightforward technique to apply, and the number of loci that can be examined is unlimited. RAPD analysis is viewed as having a number of advantages over RFLPs and other techniques. The ease and simplicity of the RAPD technique make it ideal for genetic mapping in plant and animal breeding programs, and DNA fingerprinting, with particular utility in the field of population genetics. RAPD analysis would be very useful in breeding for rapid and easy verification of hybridity in large seedling population and even purity testing of different seed lots of pulses and cereals.

\section{Materials and Methods}

\section{Plant material}

For the present experimental study 11 genotypes of cowpea (Vigna unguiculata (L.) Walp.) selected from the germplasm collected from Rajasthan College of Agriculture, Udaipur(Raj) and Department of Agricultural Botany, Dapoli (MS) the research farm of the Department of Agricultural Botany, College of Agriculture, Dapoli. All the 11 genotypes of cowpea were grown in the field. The leaf samples for DNA isolation were collected from 15 days old seedlings.

\section{DNA extraction}

The genomic DNA was isolated from the young newly flushing leaves by following the protocol of Doyle and Doyle (1990) i.e. Rapid method. Purification of DNA was done to remove RNA, proteins and polysaccharides which were the major contaminants. RNA was removed by RNase treatment. RNase was added to the DNA sample @ $100 \mathrm{ug} \mathrm{ml}^{-1}$ and incubated at $37^{\circ} \mathrm{C}$ for $1 \mathrm{hr}$. Concentration of DNA in the sample was determined by agarose gel electrophoresis with standard DNA i.e., uncut lambda DNA on 0.8per cent agarose gel and by comparison of the intensity of staining with ethidium bromide.

\section{RAPD analysis}

PCR amplification reactions were performed with random decamer primers obtained from Operon Technology (Alamenda, USA) in an Eppendorf, Master cycler gradient (Hamburg Germany). A total of 20 RAPD primers were subsequently used for PCR amplification. For the RAPD analysis, initially the PCR master mix was standardized for each PCR component and the optimum concentration of each component in master mix which gave better amplification was used for further work. PCR reaction was performed in $10 \mu \mathrm{l}$ reaction mixture consisting $3 \mathrm{U}$ TaqDNA polymerase (Banglore Genei Ltd.), 1.25 $\mu 110 \mathrm{x}$ Taq assay buffer with $0.25 \mu \mathrm{l} \mathrm{MgCl}_{2}, 10 \mathrm{mMd}$ NTPs $0.50 \mu 1,25$ pmoles of random decamer primer $0.50 \mu 1$ and $30-50 \mathrm{ng}$ of template DNA 1.0 $\mu$ l. The amplification profile for RAPD consisted of initial denaturation at $94^{\circ} \mathrm{C}$ for 5 min, followed by 35 cycles comprising of a denaturation step at $94^{\circ} \mathrm{C}$ for $30 \mathrm{sec}$, an annealing step at $37{ }^{\circ} \mathrm{C}$ for $1 \mathrm{~min}$ and an extension step at $72{ }^{0} \mathrm{C}$ for $30 \mathrm{sec}$. The cycling program was terminated by a final extension step at $72{ }^{0} \mathrm{C}$ for $7 \mathrm{~min}$. The amplified products in RAPD reaction were separated by electrophoresis in 2 per cent agarose gel (SRL, India), containing ethidium bromide in 1x TAE Buffer ( $\mathrm{pH}$ 8.0) and separation was carried-out by applying constant voltage of 80 volts for $1 \mathrm{hr}$. The standard DNA ladder used was $\Phi$ x174/Hae III digest. PCR and gel electrophoresis were carried out two times and only reproducible 
patterns were used for data analysis. The gels were photographed under UV light using Pentax K $312 \mathrm{~nm}$ camera. The images of gels were also taken by the documentation systems (Uvi-Tech. Fire reader, Cambridge, England) and saved in computer for further analysis.

\section{Data analysis}

RAPD markers across the 11genotypes were scored for their presence (1) or absence (0) of bands for each primer. By comparing the banding patterns of genotypes for a specific primer, genotype-specific bands were identified and faint or unclear bands were not considered. The binary data so generated was used to estimate the levels of polymorphism by dividing the number of polymorphic bands by the total number of scored bands. Pairwise similarity matrices were generated by Jaccard's coefficient of similarity by using MVSP-A Multivariate Statistical Package 5785 (Version 3.1). The cluster analysis was performed from the distance matrix using Jaccard's similarity coefficients.

\section{Results and Discussion}

The RAPD profiles for all 11 cowpea parents were generated with 20 random decamer primers out of which15 primers gave scorable DNA fragments. A total of 476 amplified products were observed out of which 367 were polymorphic. The number of amplified DNA fragments for each primer varied from 20 to 51, with an average of 31.73 fragments per primer. The highest number of fragments (i.e. fifty-one) was generated by primer OPA13 while OPA-18 generates 50 DNA fragments with $100 \%$ polymorphism. The percentage of polymorphism ranged from 35.29 to $100 \%$ with an average of $79.96 \%$. (Table 1) Size of the amplified products ranged from $167 \mathrm{bp}$ to $3300 \mathrm{bp}$. The primers OPA-02, OPA-03, OPA-10, OPA-11, OPA16 and OPA-18 produced distinct RAPD patterns (100\% polymorphism) for all the 11 parents. The three primers OPA-07(86\%), OPA-02 and OPA-18 (80\%) had the highest polymorphic information content value. Similar results have also been reported by Phansak et al., (2005) Patil et al., (2013) Fall et al., 2003. The percentage of polymorphism across the cowpea genotypes ranged from 35.29-100 per cent. Karuppanapandian et al., (2006) recorded similar results in cowpea landraces (25-100\%). The monomorphic fragments were constant bands and cannot be used to study diversity while polymorphic fragments reveal differences and can be used to examine and establish systematic relationship among the genotypes. The high genetic diversity detected in the cowpea genotypes analysed, probably indicated that cultivars were originally generated by different ancestors of cowpea in the past.

The similarity co-efficient ranged from 0.328 (between genotype CPD-220 and CPD-25, CPD-31 and CPD-25) to 0.613 (between genotype GS-9240 and NKO-32) indicated the distinctness (Table 2) which indicates there was high variability among the cowpea genotypes under study. These genotypes could be useful in future breeding programmes. Previous studies using allenozymes, RAPD and microsatellites, indicated a low level of variation in cowpea reported by Li et al., (2001); Pasquet, (2000); Tosti and Negri, (2002), while Patil et al., (2013) and Anatala et al., (2014), reported high level of variation among the genotypes studied. The genotypes CPD-220, CPD-25, CPD-31 and CPD-25 showed very minimum differences between them at genotypic level.

The cluster analysis based on the similarity co-efficient clearly distinguished all the 11 genotypes into two groups. The first cluster included only single genotypeCPD-25and was most diverse from rest of the 10 genotypes (Fig. 1). The second cluster further subdivided into two subclasses (Fig. 2-6). 
Table.1 Primer wise amplification and percent polymorphism of Cowpea genotypes.

\begin{tabular}{|c|c|c|c|c|c|c|c|}
\hline Sr No & $\begin{array}{l}\text { Name of } \\
\text { Primer }\end{array}$ & $\begin{array}{l}\text { Number of } \\
\text { fragments }\end{array}$ & $\begin{array}{c}\text { Number of } \\
\text { monomorphi } \\
\text { c fragments }\end{array}$ & $\begin{array}{c}\text { Number of } \\
\text { polymorphic } \\
\text { fragments }\end{array}$ & $\begin{array}{c}\text { Polymorphism } \\
\text { percentage }\end{array}$ & $\begin{array}{l}\text { PIC } \\
\text { value }\end{array}$ & $\begin{array}{c}\text { Range of } \\
\text { amplification }\end{array}$ \\
\hline 1 & OPA 02 & 20 & 0 & 20 & 100 & 0.80 & $947-3300$ \\
\hline 2 & OPA 03 & 36 & 0 & 36 & 100 & 0.77 & $399-1210$ \\
\hline 3 & OPA 04 & 31 & 11 & 20 & 64.52 & 0.45 & $415-808$ \\
\hline 4 & OPA 05 & 32 & 11 & 21 & 65.63 & 0.50 & $822-1959$ \\
\hline 5 & OPA 07 & 37 & 0 & 37 & 100 & 0.86 & $461-1900$ \\
\hline 6 & OPA 08 & 31 & 0 & 31 & 100 & 0.68 & $439-1422$ \\
\hline 7 & OPA 09 & 31 & 11 & 20 & 64.52 & 0.45 & $637-1991$ \\
\hline 8 & OPA 10 & 18 & 0 & 18 & 100 & 0.44 & $492-738$ \\
\hline 9 & OPA 11 & 17 & 0 & 17 & 100 & 0.41 & $555-1802$ \\
\hline 10 & OPA 12 & 45 & 22 & 23 & 51.11 & 0.52 & $167-1747$ \\
\hline 11 & OPA 13 & 51 & 33 & 18 & 35.29 & 0.38 & $863-1748$ \\
\hline 12 & OPA 15 & 28 & 11 & 17 & 60.71 & 0.35 & $674-1794$ \\
\hline 13 & OPA 16 & 24 & 0 & 24 & 100 & 0.62 & $773-2108$ \\
\hline 14 & OPA 18 & 50 & 0 & 50 & 100 & 0.80 & $395-1798$ \\
\hline \multirow[t]{3}{*}{15} & OPA 19 & 25 & 11 & 15 & 57.69 & 0.27 & $610-1601$ \\
\hline & Total & 476 & 110 & 367 & 1199.47 & 8.3 & \\
\hline & Average & 31.73 & 7.33 & 24.47 & 79.96 & 0.55 & \\
\hline
\end{tabular}

Table. 2 Genetic distances based on RAPDs pooled over the 15 primers in cowpea parents

\begin{tabular}{|l|l|l|l|l|l|l|l|l|l|l|l|}
\hline & $\begin{array}{l}\text { PCP } \\
\mathbf{9 7 1 0 2}\end{array}$ & $\begin{array}{l}\text { GS } \\
\mathbf{9 2 4 0}\end{array}$ & $\begin{array}{l}\text { NKO } \\
\mathbf{3 2}\end{array}$ & $\begin{array}{l}\text { CPD } \\
\mathbf{2 1 9}\end{array}$ & $\begin{array}{l}\text { CPD } \\
\mathbf{2 2 0}\end{array}$ & $\begin{array}{l}\text { CPD } \\
\mathbf{1 7 2}\end{array}$ & $\begin{array}{l}\text { CPD } \\
\mathbf{3 1}\end{array}$ & $\begin{array}{l}\text { CPD } \\
\mathbf{1 9 3}\end{array}$ & $\begin{array}{l}\text { CPD } \\
\mathbf{1 7 3}\end{array}$ & $\begin{array}{l}\text { CPD } \\
\mathbf{2 5}\end{array}$ & $\begin{array}{l}\text { CPD } \\
\mathbf{8 3}\end{array}$ \\
\hline PCP 97102 & 1.000 & & & & & & & & & & \\
\hline GS 9240 & 0.500 & 1.000 & & & & & & & & & \\
\hline NKO 32 & 0.565 & 0.613 & 1.000 & & & & & & & & \\
\hline CPD 219 & 0.475 & 0.429 & 0.567 & 1.000 & & & & & & & \\
\hline CPD 220 & 0.492 & 0.400 & 0.532 & 0.518 & 1.000 & & & & & & \\
\hline CPD 172 & 0.500 & 0.453 & 0.590 & 0.526 & 0.443 & 1.000 & & & & & \\
\hline CPD 31 & 0.467 & 0.492 & 0.583 & 0.574 & 0.483 & 0.492 & 1.000 & & & & \\
\hline CPD 193 & 0.518 & 0.443 & 0.438 & 0.414 & 0.407 & 0.417 & 0.456 & 1.000 & & & \\
\hline CPD 173 & 0.600 & 0.444 & 0.557 & 0.545 & 0.536 & 0.517 & 0.564 & 0.431 & 1.000 & & \\
\hline CPD 25 & 0.411 & 0.439 & 0.344 & 0.357 & 0.328 & 0.362 & 0.328 & 0.396 & 0.400 & 1.000 & \\
\hline CPD 83 & 0.526 & 0.385 & 0.424 & 0.377 & 0.491 & 0.359 & 0.466 & 0.491 & 0.491 & 0.407 & 1.000 \\
\hline
\end{tabular}


Fig.1 Dendrogram depicting 11 cowpea parents based on the genetic distances generated by 15 random primers

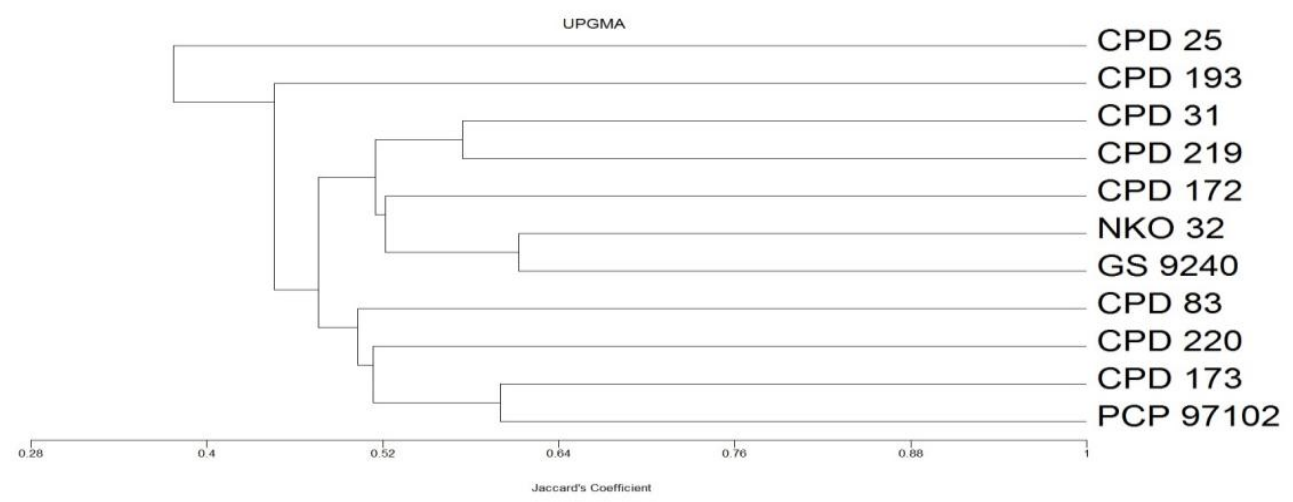

Fig.2 RAPD profile pattern of eleven cowpea parents using primer OPA-07

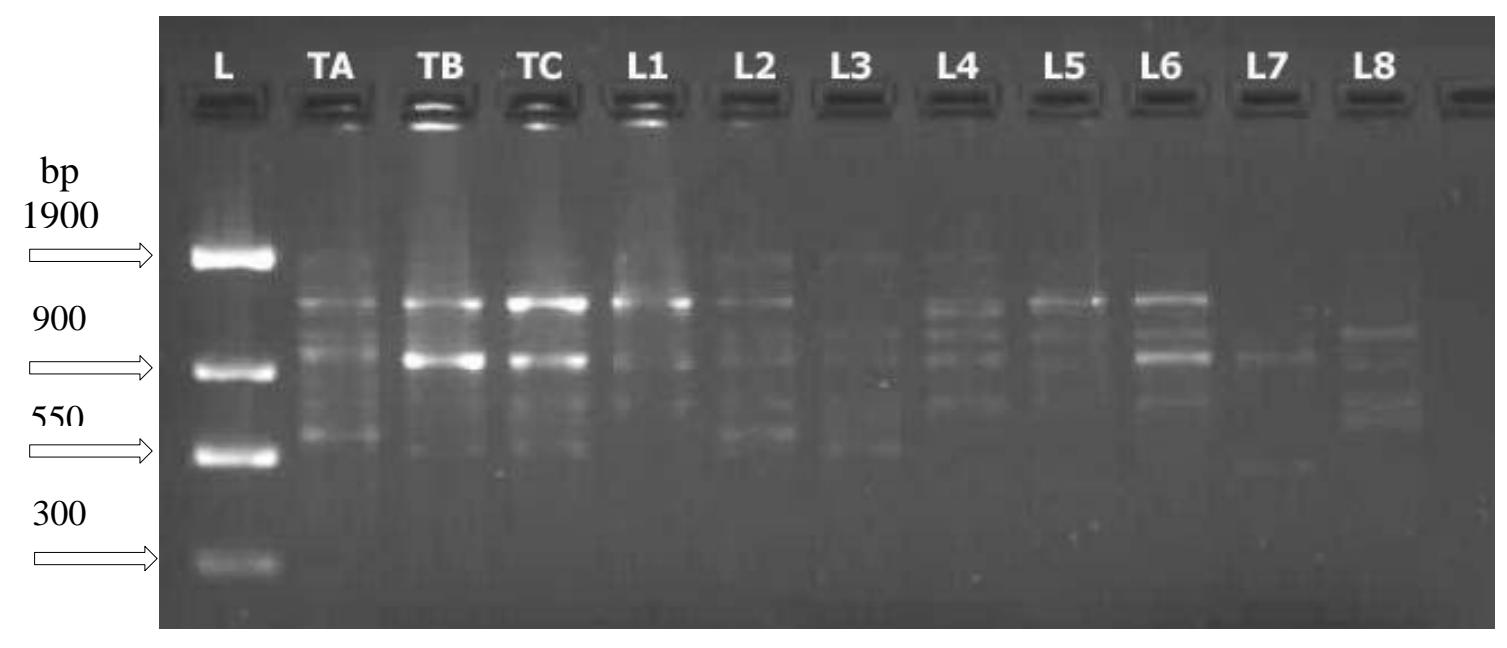

Fig.3 RAPD profile pattern of eleven cowpea parents using primer OPA-09




Fig.4 RAPD profile pattern of eleven cowpea parents using primer OPA-12

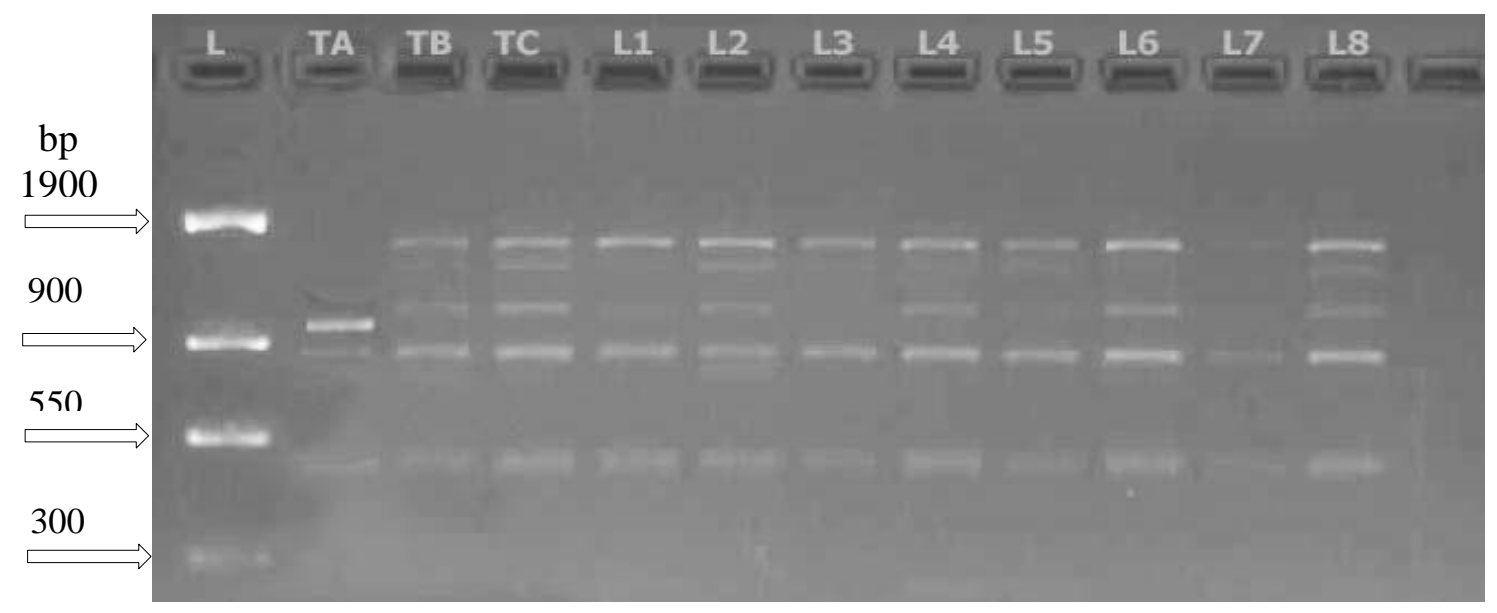

Fig.5 RAPD profile pattern of hybrid 13, 14 and 15 alongwith their parents- primer OPA-18

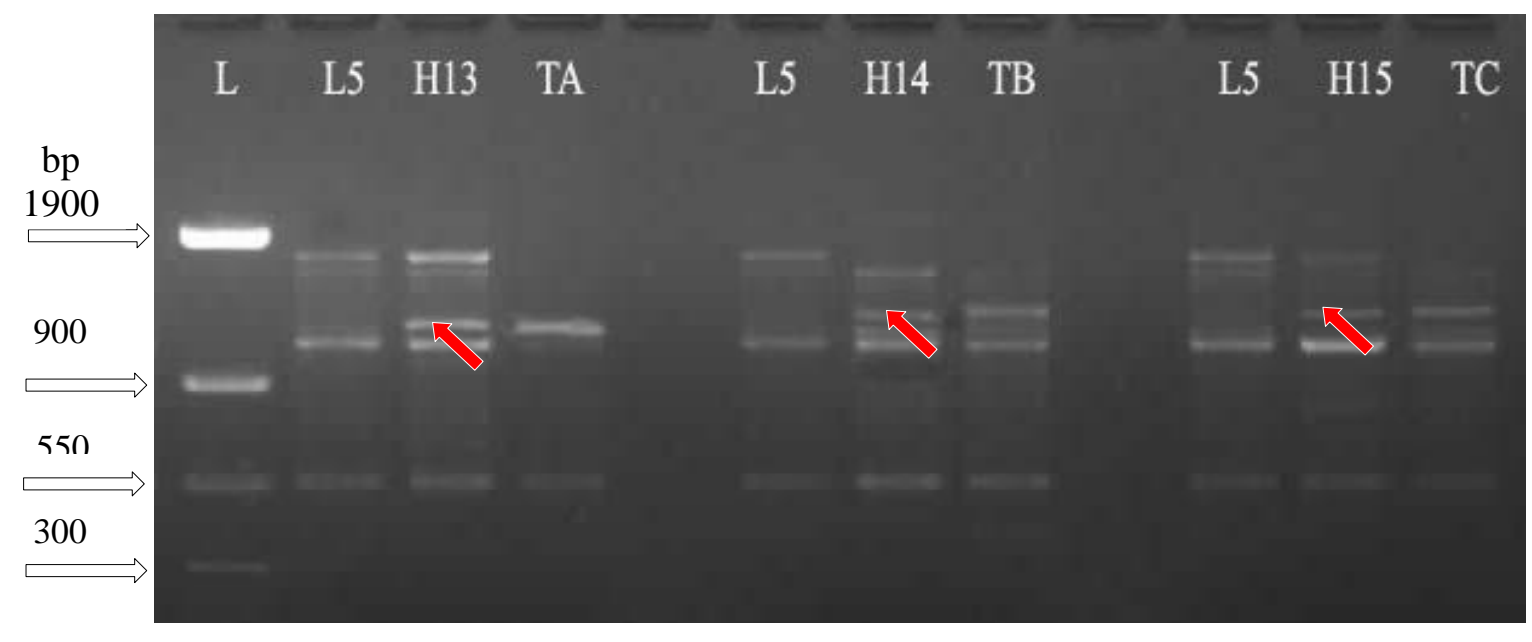

Fig.6 RAPD profile pattern of hybrid 22, 23 and 24 along with their parents- primer OPA-18

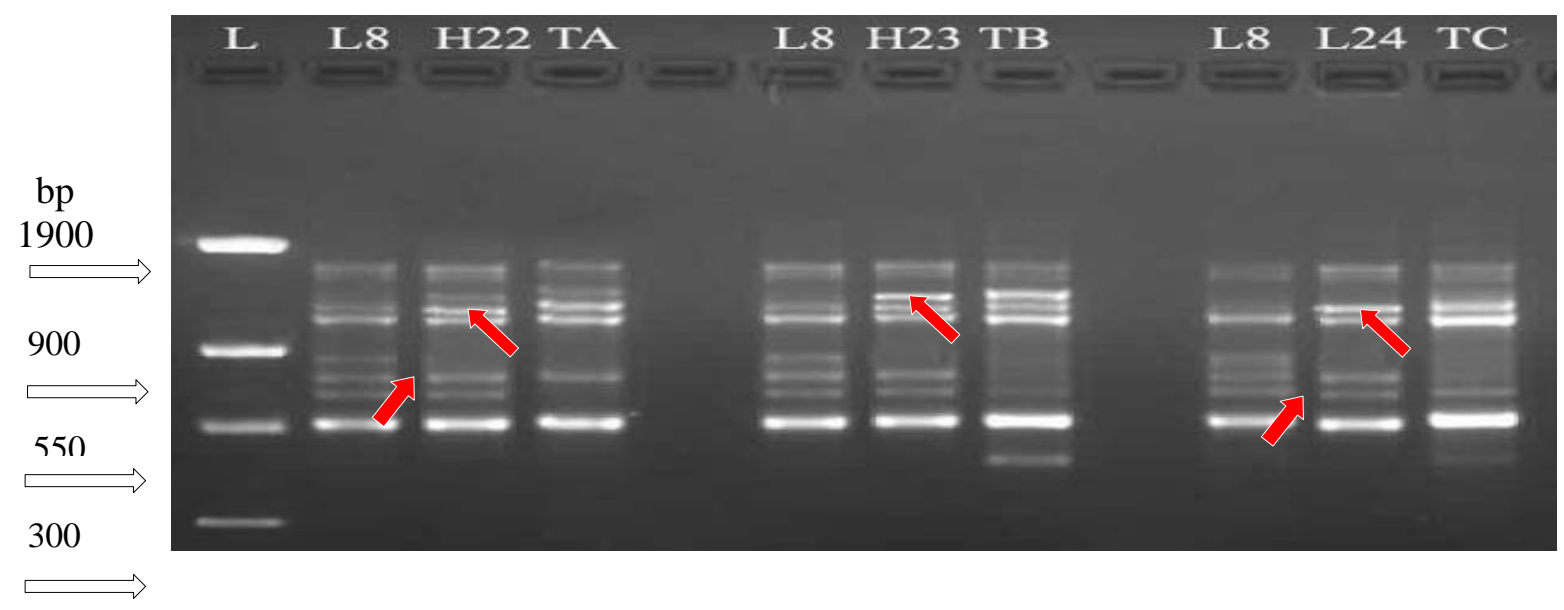


The first sub class of the second cluster included only one genotype i.e CPD- 193. The second sub class again subdivided into two sub class, the first sub class (IIBa) consists of 5 genotypes i.e. CPD-31, CPD219, CPD-172, NKO-32, GS-9240 while the second sub class (IIBb) was formed with remaining 4 genotypes namely; CPD-83, CPD-220, CPD-173, PCP-97102.From the above clusters formed it was observed that, the genotype CPD-25 was more diverse from other 10 genotypes of cowpea. Patil et al., (2013) reported the RAPD profile of 30 cowpea genotypes grouped into two main clusters (I and II). The first cluster (I) was formed by the single genotype and the rest of 10 genotypes were included in to second cluster (II). Dendrogram revealed that the genotypes GS-9240 and NKO-32 were diverse and useful in future hybridization programme of cowpea.

The hybrid specific bands generated in RAPD analysis by primer OPA-18 was used for the identification particular $\mathrm{F}_{1}$ hybrid of cowpea. The results obtained from RAPD fingerprinting were found to be useful to hybrid purity analysis, identification of hybrids and parentage confirmation. There is no previous report of utilization of RAPD markers for purity assessment of hybrids or hybrid identification in cowpea.

In conclusion, molecular markers can be exploited to generate the fingerprint database which can be utilized for analyzing the viability and purity of the seeds. This may result in the improvement of both, quality and quantity of crops. The RAPD technique appears to be the best alternative tool to assess genetic diversity, because it provides good discrimination in short time and at low cost. Critical analysis of the results obtained during present studies reveals that Vigna unguiculata genotypes could be efficiently characterized and classified using RAPD markers and by analyzing the banding pattern of the amplified products. The genotype GS9240 and NKO-32 were diverse genotype while genotype CPD-25 observed as a unique genotype. These genotypes would be further exploited for vigna crop improvement. The RAPD primer OPA-18 was effectively used for confirmation of hybridity.

\section{References}

Anatala, T.J., Gajera, H.P., Savaliya, D.D., Domadiya, R.K., Patel, S.V. and. Golakiya, B.A. 2014. Molecular diversity analysis of cowpea (Vigna unguiculata L.) genotypes determined by ISSR and RAPD markers, International Journal of Agriculture, Environment \& Biotechnology. 7(2): 269-276.

Doyle, J. J. and Doyle, J. L. 1990.Isolation of plant DNA from fresh tissue.Focus.,12: 13-15.

Fall, L., Diouf, D., Fall, N. M., Bediane, F. A. and Gueye, M. 2003. Genetic diversity in cowpea (Vigna unguiculata L. Walp.) varieties determined by ARA and RAPD techniques. African Journal of Biotechnology. 2(2): 48-50.

Karuppanapandian, T., Karuppudurai T., Sinha P. B., Haniya A. M. K. and Manoharan K. 2006. Phylogenetic diversity and relationships among cowpea (Vigna unguiculata (L) Walp.) landraces using Random amplified polymorphic DNA markers. Gen. appl. plant physiology., 32(3-4): 141-152.

Li, C.D., Fatokun., C.A., Ubi, B.S., Singh, B.B. and Scoles, G. 2001.Determining genetic similarities among cowpea breeding lines and cultivars by microsatellite markers. Crop Science41: 189-197.

Pasquet, R.S. 2000. Variation at isozyme loci in wild Vigna unguiculata (L.) Walp. (Fabaceae, Phaseoleae). Plant Syst. 
Evol.186: 157-173

Patil, D. M., Sawardekar S.V., Gokhale N. B., Bhave S. G., Sawant, S. S, Sawantdesai, S. A., Lipne, K. A., Sabale, S. N. and Joshi, S.N. (2013). Genetic diversity analysis in cowpea (Vigna unguiculata (L.)Walp.) by using RAPD markers .International Journal of Innovative Biotechnology and Biochemistry. 1(1): 15-23

Phansak, P., Taylor, W.J. and Mongkolpom,
O. 2005. Genetic diversity in yardlong bean (Vigna unguiculata ssp. sesquipedalis) and related Vigna species using sequence tagged microsatellite site analysis. Sci. Hortic. 106: 137-146.

Tosti N. and Negri V. 2002. Efficiency of PCR-based markers in assessing genetic variation among cowpea (Vigna unguiculata subsp. unguiculata) landraces. Genome., 45: 268-275.

\section{How to cite this article:}

Pethe, U. B., N. S. Dodiya, S. G. Bhave and Sawardekar, S. V. 2020. RAPD Analysis for Genetic Diversity and Verification of Hybridity in Cowpea [Vigna unguiculata (L.) Walp.]. Int.J.Curr.Microbiol.App.Sci. 9(08): 2442-2449. doi: https://doi.org/10.20546/ijcmas.2020.908.279 